$\mathbb{T}$ periodica polytechnica

\author{
Architecture \\ $38 / 2$ (2007) 73 , 77 \\ doi: 10.3311/pp.ar.2007-2.05 \\ web: http://www.pp.bme.hu/ar \\ (c) Periodica Polytechnica 2007 \\ RESEARCH ARTICLE \\ Gábor Becker \\ Received 2005-04-29
}

\section{The morphology of the glass roof}

\begin{abstract}
This article reviews a possible classification of glass roofs. The discussed classifications and enumerations try to contribute to a practically complete survey, the opportunities for glass roofs and the applicable structural solutions.
\end{abstract}

\section{Keywords}

glass roofs $\cdot$ morphology $\cdot$ roof constructions

\section{Gábor Becker}

Department of Building Constructions, Faculty of Architecture, BME, H-1111 Budapest Múegyetem rkp. 3., Hungary

e-mail: becker@arch.bme.hu
Glass roofs today have become common elements of architecture. Although these are rapidly developing constructions, it is perhaps timely to attempt to make a systematic survey. This brief script tries to align all the opportunities, which we think useful both for designers and teachers of construction. At the same time we want to stress that this classification refers to the present day's standard and the opportunities for constructions have not yet been exploited.

\section{Influences effecting glass roofs}

Glass roofs are exposed to the same impacts as any flat surface or roof in a built up area, however it still seems useful to enumerate these for the sake of a better perspective when designing glass constructions.

The most relevant impacts are of meteorological character:

- Precipitation in form of rain, snow, melted snow, hail storms etc.

- Solar radiation outside of the visible light spectrum and heat radiation. From the structural point of view an important factor is the ultraviolet radiation that results in an accelerated ageing of the materials (surface covers, sealants).

- The wind effect primarily acts as dynamic factor (when dimensioning of load bearing structures), nevertheless gales combined with heavy rain are of considerable importance from a structural point of view when designing constructions.

From the external effects the most important are:

- Chemicals, corrosive influences, the source of which is primarily pollution.

- Dust, stains, dirt, impurities, contamination may significantly effect the transparency requested by the designer.

- Mechanical impacts which are differentiated as constant (running and to shop windows), occasional - occurring with the maintenance and finally the damaging impacts from heavy objects.

- Users are more sensitive to the noise, so this also deserves attention. 
- Fire This is only briefly mentioned (there are existing glass roofs with considerable fire resistance, heat-protected cladding of the glazing bars, or they can act as separate fire guard. However we will not be dealing with these aspects here)

Effects derived from the difference between external and internal air conditions:

- Thermal difference that may cause stresses and changes in shape and dimensions and

- The difference in vapour pressure, the limiting of which is a structural task.

\section{A possible classification for glass roofs}

With a view to design and education we want to attempt to cover a complete classification of the glass roofs.

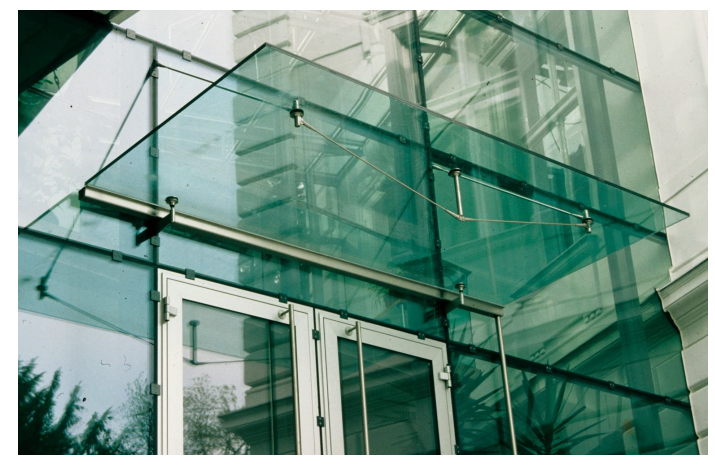

Fig. 1. Canopy roof - trussed construction

\subsection{Dimensions and application}

At this stage the criteria for classification of the constructions are: frequency and size.

- Canopy roofs: the size of which is generally moderate, although there are fairly large canopy roofs in existence. They may have different characters; nevertheless their basic function is protection against precipitation. (See Fig. 1).

- Skylights (roof-lights): they may be tubular, linear or planar. The tubular type (light-wells) may have different heights and forms - the linears are single (like sheds) or double pitch monitor (with different inclinations) or of cradle vault character.

- Conservatories. They are not a separate group, nevertheless because of their frequency, they deserve discussion. Their size is like common internal spaces with 2-5 m depth, characteristically they lean against a wall. Roof panes are continuous in the direction of slope. They may be constructed exclusively with glazing bars or a framed-ribbed construction. In the later case the glazing bars are supported by a load bearing structure. There are many patented bar sections made of aluminium or plastics with an extended height specifically for conservatories, thus both ready made and custom made alternatives are available.
- Separate glass roofs (generally planar) which as detailed later serve as glass covers for larger spaces.

- Complex glass constructions are buildings or part of a building where not merely the roof is glazed, but all the other cladding structures (walls or even floors)are made of glass or adjoining to it.

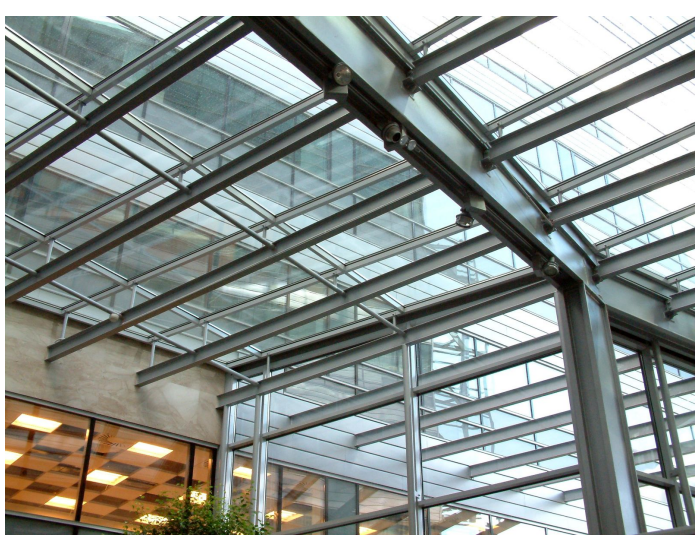

Fig. 2. Loadbearing structure + glazing bar construction roof.

\subsection{Based on performance}

This includes the following major types of glass constructions:

\section{- Canopy roofs}

- Protecting roof - both of these serve as protection against precipitation (effectively the function of an umbrella)

- Spaces with varying air conditions, i.e. not for permanent human use, for enclosuring of unheated or just open spaces (unheated halls, waiting halls etc.)

- Constructions providing full performance - enclosure for permanent human habitation, to cover heated spaces, the requirements of which include complete environmental control.

\subsection{Construction - The design of loadbearing structures}

- Loadbearing structures + glazing bar construction roofs. With these constructions the loadbearing structure of the roof is separated from the metal structure incorporating the glazing. This is the prevailing structure for large glazed roofs. (See Fig. 2). The glazing bars maybe borne upon a load bearing structure, that may be an arch or vault, a flexurally stressed beam, trussed construction, cable net structure with appropriate internal or external glass fixing devices or alternatives with glazing bars.

- Glass roofs, using exclusively glazing bars is the usual method for smaller type glass roofs, where the glazing bars are also the loadbearing structures and there is no separate bearing component.

- From a structural point of view an extraordinary solution is the one that is suitable to cover large spaces, characteristic of 
it is that the single or double curved surface ribs at the nodes are connected with tie cables. This way the lattice shell is created. Visually only the ribs are exposed, but the stressing cables maintain the shape and bear the loads. (See Fig. 3.

- Also in the last alternative the glass shares the bearing loads and enables the structure to be minimized. Such are the hanging trussed glass pane structures, plain-, cradle vaulted-, or spherical constructions.

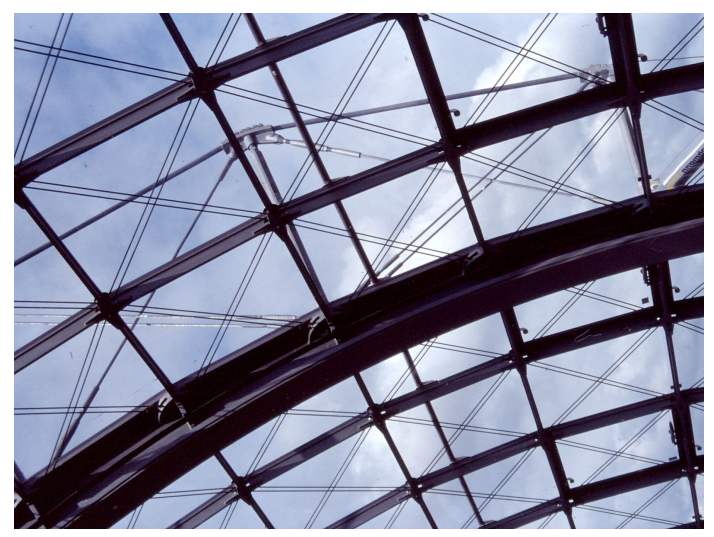

Fig. 3. Lattice shell construction.

\subsection{The fixing of the glass}

- The most frequent solution for firmly holding the glass panes is - fasteners on two or all the four sides - generally used in curtain-walls.

- To provide a plain upper surface, the upper fastener sections are omitted and the glass panes are only supported at the sides. In this case wind suction is compensated by adhesion at certain points, and with mechanical fasteners especially at those arises and corners most exposed to the wind.

- The glass panes can also be fixed at specific points. For this purpose, several alternatives are available. Along the arises and corners and through bored holes, with the application of special individual fittings manufactured to this end. (See Fig. 4). The fastening points - depending on how it relates to the load bearing structure - can be a horizontal support or suspension.

\subsection{The material of the immediate glass bearing structure}

- Wooden ribs are nowadays rarely used and only for small scale glass roofs, but even in this case external cladding is needed for protection against precipitation, UV radiation and radiant heat. On external horizontal surfaces wood is inappropriate for fastening or as a cover. On the usually laminatedtimber ribs aluminium or plastic fasteners are fitted, in this way the construction has internally a wood and externally an aluminium or plastic appearance.

- As immediate bearing structures most frequently metal (aluminium, steel) rib-sections are applied. These are mainly curtain wall type sections, but also individual ribs, or overhead

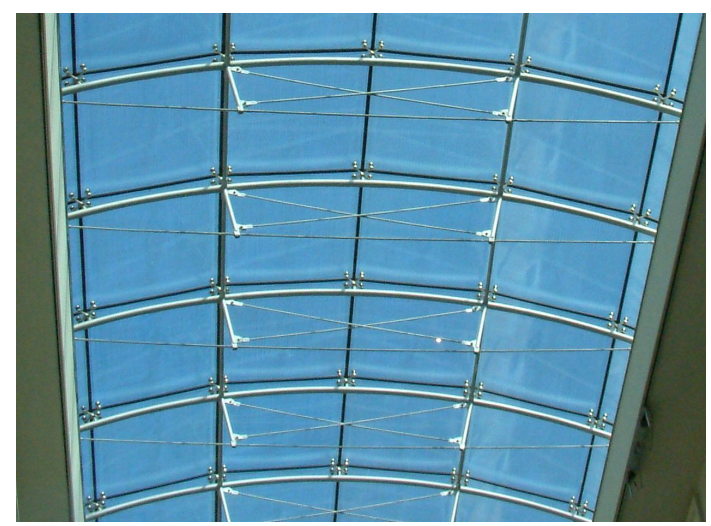

Fig. 4. Fixed point roof construction.

rails are utilized. The earlier mentioned lattice shell structure also belongs here.

- The direct fasteners of point fastened glass roofs create a point fastened system; the bearing construction of it can be rigid but more frequently a pre-stressed cable system, made of steel cable, usually completed with compressed rods. Glass panes can be provided with a hanging truss, considerably improving the bearing capacity of the panes and consequently the applicable spans as well.

- Comparatively rare, but structurally interesting is the glazing method of the double curved cable nets. Because of the different size and shape of the grid it is glazed with individual glass fasteners.

- The bearer of the glass pane itself can also be of glass, recently and more frequently glass beams are used to support glass fields. (See Fig. 5).

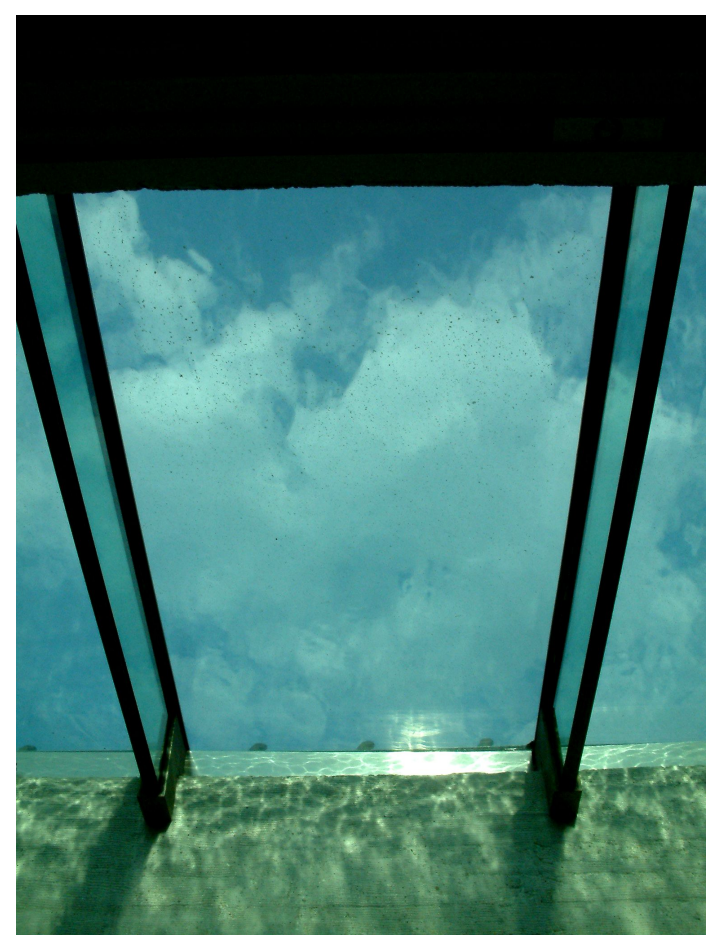

Fig. 5. Glass fields supported by glass beams. 


\section{Comprehensive tables}

Tab. 1. Influences on glass roofs

\begin{tabular}{ll}
\hline \multirow{3}{*}{ Meteorological impacts } & precipitation (rain, snow) \\
\cline { 2 - 2 } & sun radiation (heat, UV radiation, light) \\
\hline wind \\
\hline
\end{tabular}

Temperature differences

Vapour pressure differences

Dust, stain impurities

Chemical effects

\begin{tabular}{ll}
\hline \multirow{3}{*}{ Mechanical impacts } & \multicolumn{1}{c}{ constant (running) } \\
\cline { 2 - 2 } & those occurring with the maintenance \\
\hline Noise & \\
Fire & \\
\hline
\end{tabular}

Tab. 2. Classification of glass roofs

\begin{tabular}{|c|c|c|}
\hline \multirow{7}{*}{ according to size and application } & canopy roofs & \\
\hline & & tubular \\
\hline & roof lights & linear \\
\hline & & windows in the roofing plane \\
\hline & conservatories & \\
\hline & separate glass roofs & \\
\hline & complex glass constructions & \\
\hline \multirow{4}{*}{$\begin{array}{l}\text { classification based on performance } \\
\text { criteria }\end{array}$} & canopy & \\
\hline & protecting roof & \\
\hline & transitory spaces & \\
\hline & full environmentally controlled enclosures & \\
\hline \multirow{6}{*}{ based on relation to bearing structures } & glass panes supporting ribs only & \\
\hline & & angled structures (beams) \\
\hline & separate load bearing structures + glass bars & mixed structures (vaults, trussed \\
\hline & & shells, membranes, cable nets \\
\hline & glass casements + cable constructions & \\
\hline & $\begin{array}{l}\text { the glass panes themselves are also load } \\
\text { bearing }\end{array}$ & \\
\hline \multirow{4}{*}{ based on the method of fixing } & Two / four side pressed & \\
\hline & supported at the arises & \\
\hline & at points & supported \\
\hline & & suspended \\
\hline \multirow{8}{*}{ based on the material of the casing ribs } & wood & \\
\hline & (rare, covered by metal) & \\
\hline & plastic (generally smaller construction) & \\
\hline & metal (aluminium, steel) & \\
\hline & lattice shell & \\
\hline & stressed cable systems, trussed slabs & \\
\hline & cable nets of steel & \\
\hline & glass beams & \\
\hline
\end{tabular}




\section{Some observations}

The discussed classifications and enumerations intend to contribute to a practically complete survey, the opportunities for glass roofs and the applicable structural solutions. Evidently as time goes on there will be more opportunity for further developments. Nevertheless we feel it necessary to make some brief observations referring to the basic structural rules.

The panes in glass roofs should not fall in case of damage. Theoretically this could be achieved by additional construction elements (e.g. a net) but in practice - in simpler cases - wired glass, usually laminated safety glass with a PVB foil interlayer will do.

Care must be taken to avoid the greenhouse effect: solar radiation through glazing results in a considerable heat load. This cannot be totally eliminated even with the high quality solar control glass, so shading, the natural airing of the heat cushion that develops under the internal side of the glass roof and eventually also air conditioning is necessary. All these need a complex design approach that would make the subject of another study.

\section{References}

1 Petró B, Az épületszerkezettan és az épületszerkezetek tervezése, Építésügyi Tájékoztatási Központ, Budapest, 1991.

2 Balkow, Schuler, Sobek, Glassbau Atlas/Glass Construction Manual, Birkhauser, München, 1999. 